\title{
Establishing Program Educational Objectives
}

\author{
Shivakumar $\mathbf{R}^{1}$, Usha $\mathbf{H ~ S}^{2}$, ChetanA Nayak ${ }^{3}$, Sainath $\mathbf{K}^{4}$ and Samita Maitra ${ }^{5}$ \\ ${ }^{1,2,3,4,5} \mathrm{~B}$ M S College of Engineering, Bangalore 560019, India
}

\begin{abstract}
Outcome based education establishes a method of evaluating the program education objective. The National board of Accreditation, India has laid down 12 attributes as program outcomes which suits the engineering education as per the norms of ABET accreditation system globally. The attainment of these 12 attributes as program objective will have to be mapped to the Program Educational Objective (PEO). The attainment of the program outcomesis achieved by designing the curriculum considering all the attributes so that the graduate gets trained in all the outcomes. The attainments of the PEOs are assessed by alumni, employees, graduate entrepreneurs and stake holders' survey.
\end{abstract}

Keywords - Outcome based education, program outcome, program educational objective, surveys, data analysis

\section{Shivakumar $\mathbf{R}$}

B M S College of Engineering, Bangalore 560019, India

\section{Introduction}

The National board accreditation, India (NBA) has adapted outcome based education as the main criteria for evaluating engineering programs for accreditation under Tier-1. The important part in the new criteria is Program Educational Objectives (PEOs) and Program Outcomes (POs) [1]. PEOs for specific domain experts are define with input from alumni, stake holders, parents and employer's surveys giving importants to institute vision and mission. The defined PEOs are expected accomplishments of graduates during the first several years following graduation.

The POs mainly describe about students are expectation and their ability to understand what to do by the time of graduation from the program. Both PEOs and POs need to be assessed with an expected percentage of attainment, POs are assessed at end of course for every semester by assessing the Continuous Internal Examination (CIE), semester examination, quizzes and seminar presentation on chosen topics are mapped with the defined Course Outcomes (COs) and POs. PEOs are assessed after the graduates leave the program based on the present work experience, vertical progression of the graduate in the industries and research carried out with higher education in India or abroad [2,3].

The design of the curriculum plays a major role is the assessment method for both POs and PEOs. The curriculum need be designed such that all the basic science courses will be a stepping stone for professional competence and the required 
1. Department of Chemical Engineering, BMS College of Engineering, Bangalore, India

knowledge to focus on a particular specialization upon graduation, in the work environment or in graduate school. The core domain courses should mainly focus on providing students with a broad understanding of basic concepts of the domain, as well as the contemporary skills required by industry, with inclusion of extensive laboratory experiences and many opportunities for students to work on hands-on, design projects.

In this paper we illustration that the POs are achieved by following an assessment method which includes assessing the continuous internal evaluation (CIE), end semester examination, quizzes and seminar presentation on chosen topics. Students are given a set of questions for CIE and each question paper can be articulated to indicate which question maps to the specific COs which in turn maps to a POs. The PEOs are achieved by assessing alumni, parental, employees and graduate entrepreneurs surveys after graduation.

\section{Methodology}

The design of curriculum for a specific domain is a very first step to achieve the Program Educational Objectives (PEOs). The curriculum content are broadly classified into different course components like Basic Engineering Science, Engineering science, Departmental core and design, Technology, Project, Computation and modeling and Humanities \& social sciences. These course components are mapped towards the Program Outcomes (POs) and to the Program Education Objectives (PEOs) presented in Table 1 as example for chemical Engineering discipline.

Table 1: Mapping of course components with POs and

\begin{tabular}{|c|c|c|}
\hline Course Components & PO's & PEOs \\
\hline Basic engineering science & PO1,PO2 & PEO3 \\
\hline Engineering science & PO2, PO3, PO12 & PEO3 \\
\hline Departmental core and design & PO3 & PEO1 \\
\hline Technology & PO5, & PEO1, \\
& PO6,PO7,PO12 & PEO2 \\
\hline Project & PO4,PO6, & PEO3 \\
\hline $\begin{array}{c}\text { Computation and modelling } \\
\text { Humanities and social } \\
\text { sciences }\end{array}$ & PO5,PO12 & PEO3 \\
\hline
\end{tabular}

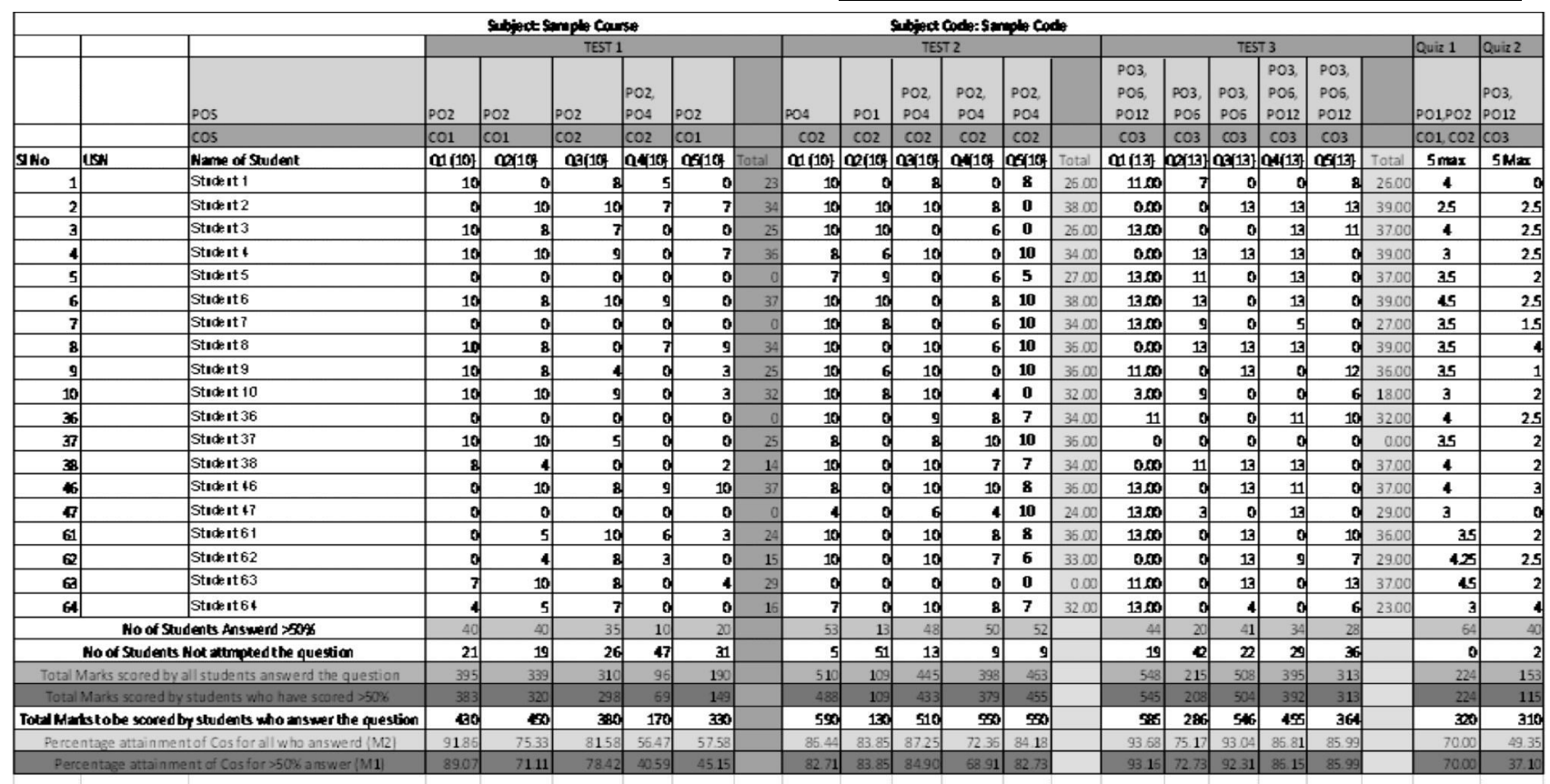

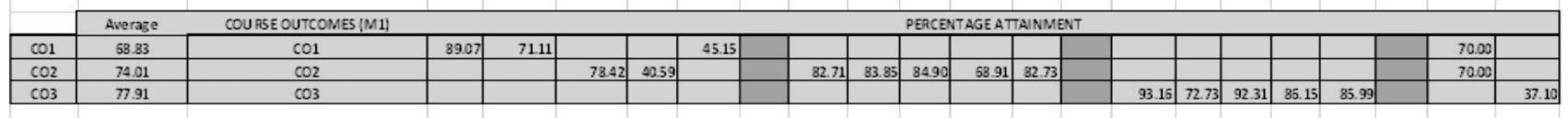

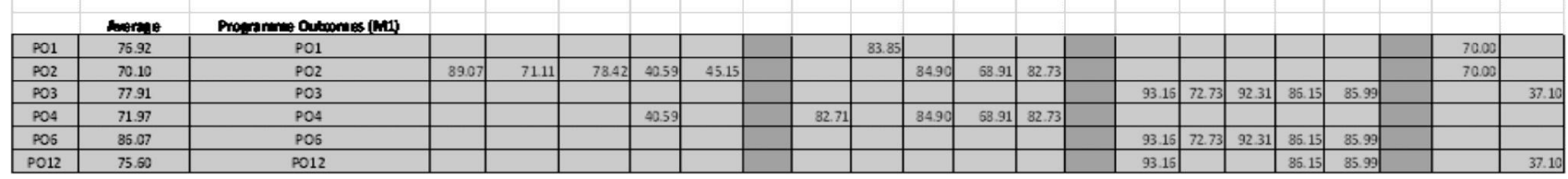

Figure 1: Program outcome quantification work sheet for a sample course 


\section{A. Program Outcome (PO) Attainment Quantification}

The assessment of the PO can be quantified by considering the continuous internal assessment marks of the individual student based on the question papers framed during the evaluation process. Tests are one of the important evaluation method adopted to assess the attainment of the program outcomes. The program outcomes can also assessed by different evaluation methods including Quizes, assignments and seminars, all these evaluation methods scores will be considered and the attainment of the PO can be quantified by using MS Excel program. A sample Excel sheet for quantification of POs is given in the Figure 1. From the Figure 1, every question from each tests conducted with quizzes are mapped to the course outcomes and these Course Outcomes(COs) are mapped to the program outcomes and the value of each COs are averaged to assess the percentage attainment of the POs as multiple POs are mapped to a particular course outcomes.
B. Program Educational Objectives (PEOs) Attainment Quantification: The program education objectives are defined by considering all the 12 graduate attributes defined by the ABET accreditation system globally and in view of institute vision and mission. The PEOs attainment is quantified by assessing the different surveys conducted by alumni, stack holders, employees and graduate entrepreneurs. The alumni survey was conducted with different questionnaires addressing to the POs indirectly and this is considered as the direct assessment method to measure the attainment of the PEOs is represented in Table 2. This survey is conducted for alumni graduated 3 years after the current academic year (CAY) i.e. (CAYm3, CAYm4, CAYm5) [2-4]. These questions are rated by the alumni as Excellent, very good, good and satisfactory and mapped to the respective PEOs. Every question is mapped to the respective PEOs is presented in Figure 2.The questions mapped to the PEOs are articulated how the question is mapped to the PEOs.

Table 2: Sample copy of Chemical Engineering Alumni Survey

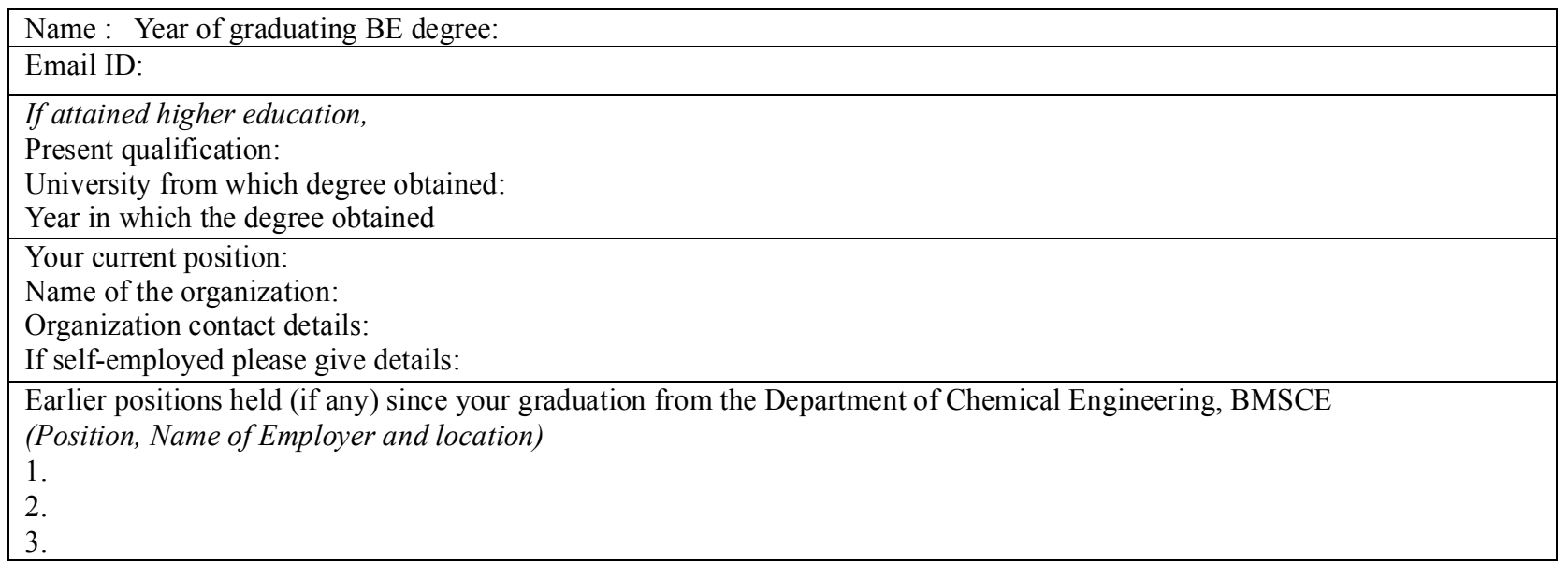

The Chemical Engineering Department, BMSCE has attempted to provide an education in Chemical Engineering and promote you as professionals. We would like to know your views about the following outcome measures to assess for continuous up-gradation/improvement.

Kindly give your response towards the role of Chemical Engineering education in each of the following?

\begin{tabular}{|c|c|c|}
\hline & & Kindly enter your response \\
\hline 1 & $\begin{array}{l}\text { Are the fundamental courses needed for your present job (like mathematics, science, basic } \\
\text { engineering etc.)? If yes, please write a brief description of its utilization }\end{array}$ & \\
\hline 2 & $\begin{array}{l}\text { Are you designing a system, component, or process to meet desired needs within realistic } \\
\text { constraints such as economic, environmental, social, political, ethical, health and safetyand } \\
\text { sustainability }\end{array}$ & $\begin{array}{l}\text { A brief description of your } \\
\text { present job details: }\end{array}$ \\
\hline 3 & $\begin{array}{l}\text { Apart from working in team of Chemical Engineers, have you worked with other engineers in any } \\
\text { stage of your professional responsibility? If yes, please indicate the team composition and time } \\
\text { duration along with the name of the Company. }\end{array}$ & \\
\hline
\end{tabular}




\begin{tabular}{|l|l|l|}
\hline 4 & Briefly give your understanding of professional and ethical responsibility & \\
\hline 5 & $\begin{array}{l}\text { Have you submitted project/research proposals for funding? If yes, please give the titles and } \\
\text { agencies where you have applied? }\end{array}$ & \\
\hline 6 & $\begin{array}{l}\text { Did the BE degree prepare you for the requirement of broad education necessary to understand } \\
\text { the impact of engineering solutions in a global, environmental, and societal context? }\end{array}$ & \\
\hline 7 & $\begin{array}{l}\text { Do you recognize the need for life-long learning related to your profession? If yes, please write } \\
\text { brief points }\end{array}$ & \\
\hline 8 & $\begin{array}{l}\text { What are the modern technical tools that you have used in your present and earlier job/research/ } \\
\text { profession? }\end{array}$ & \\
\hline
\end{tabular}
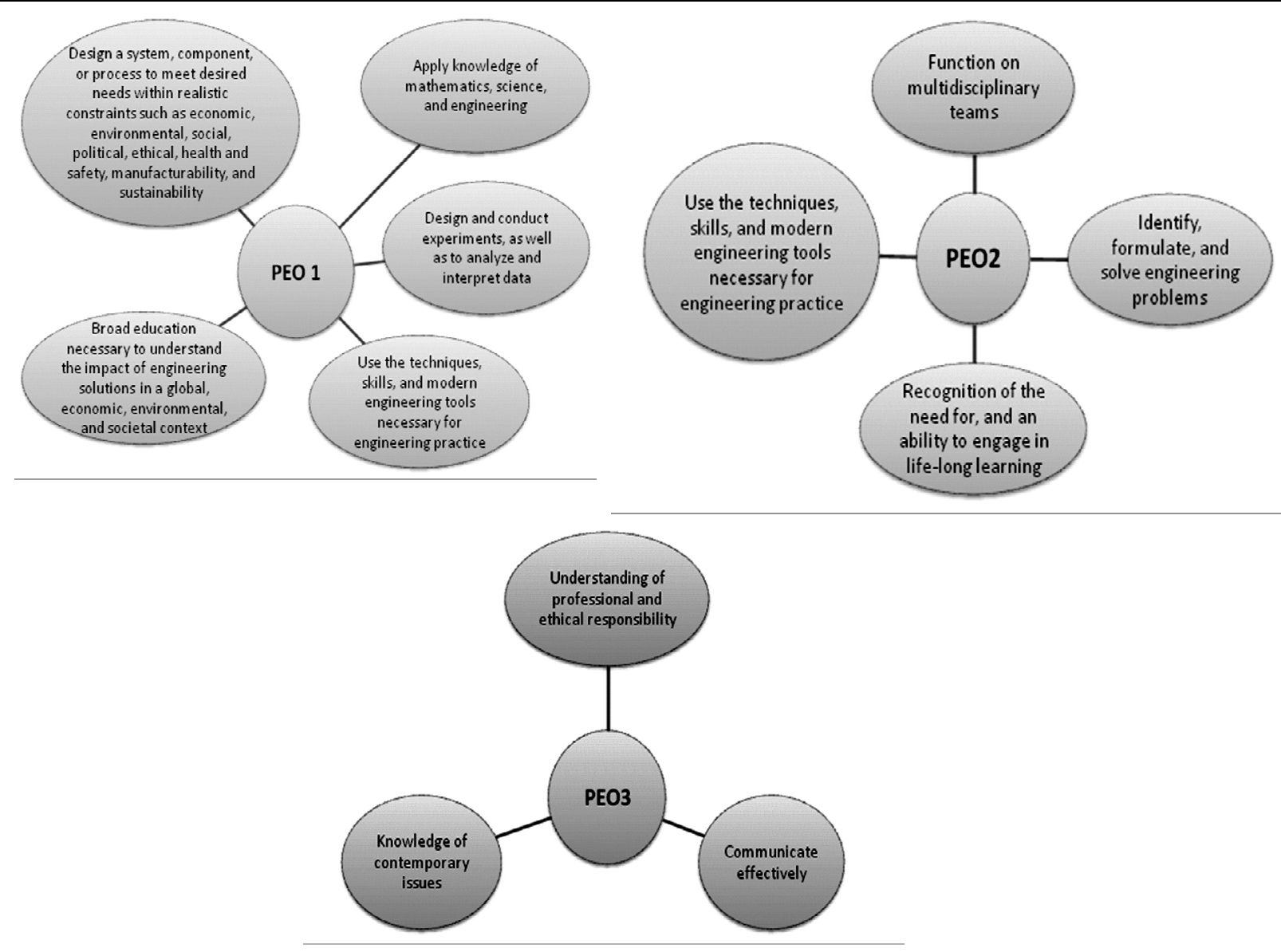

Figure 2: Mapping of alumni survey questions to PEOs

From Figure 2 we elucidate how the questions asked in survey are mapping to the PEOs. Every question describes the outcomes of the particular program and these outcomes are indirectly used to map the PEOS. Based on the average rating given by the alumni the attainment of PEO is obtained.

Figure 3provides a insight of articulation for PEO1, describing how thePEO is mapped with the questions along with the ratings in terms of percentage. The percentagesratings are the total percentage of students participated in survey and have given that rating. Based on the ratings the attainment of the PEOs can be assessed by a threshold percentage of the attainment for the PEOs[3]. The complete attainments of the PEOs are presented in the Figure 4. The mapping of other PEO are shown in Figure2.

Figure 4indicate the attainment of the PEOs which vary in percentage. This is because some of the 
graduates will work in the diversified teams for while and then move into core sector by pursuing higher education or visa versa, hence the attainment for the PEO3 is less. The Figure 4 depicts the percentage attainment of PEOs in all four academic years from 2005-2012.

Based on all these results the presently framed PEOs attainment is obtained and this exercise will continued till the threshold $60 \%$ is attained with improvements in the teaching methodologies, change in the curriculum design as the course design will have direct effect of PEOs attainment shown in Table 1 by mapping. These statistics along with the institute vision and mission the PEOs are established. And as the institute vision and mission changes the survey of alumni and stockholders will be considered and they will be reframed and attainment will assessed again by surveys.

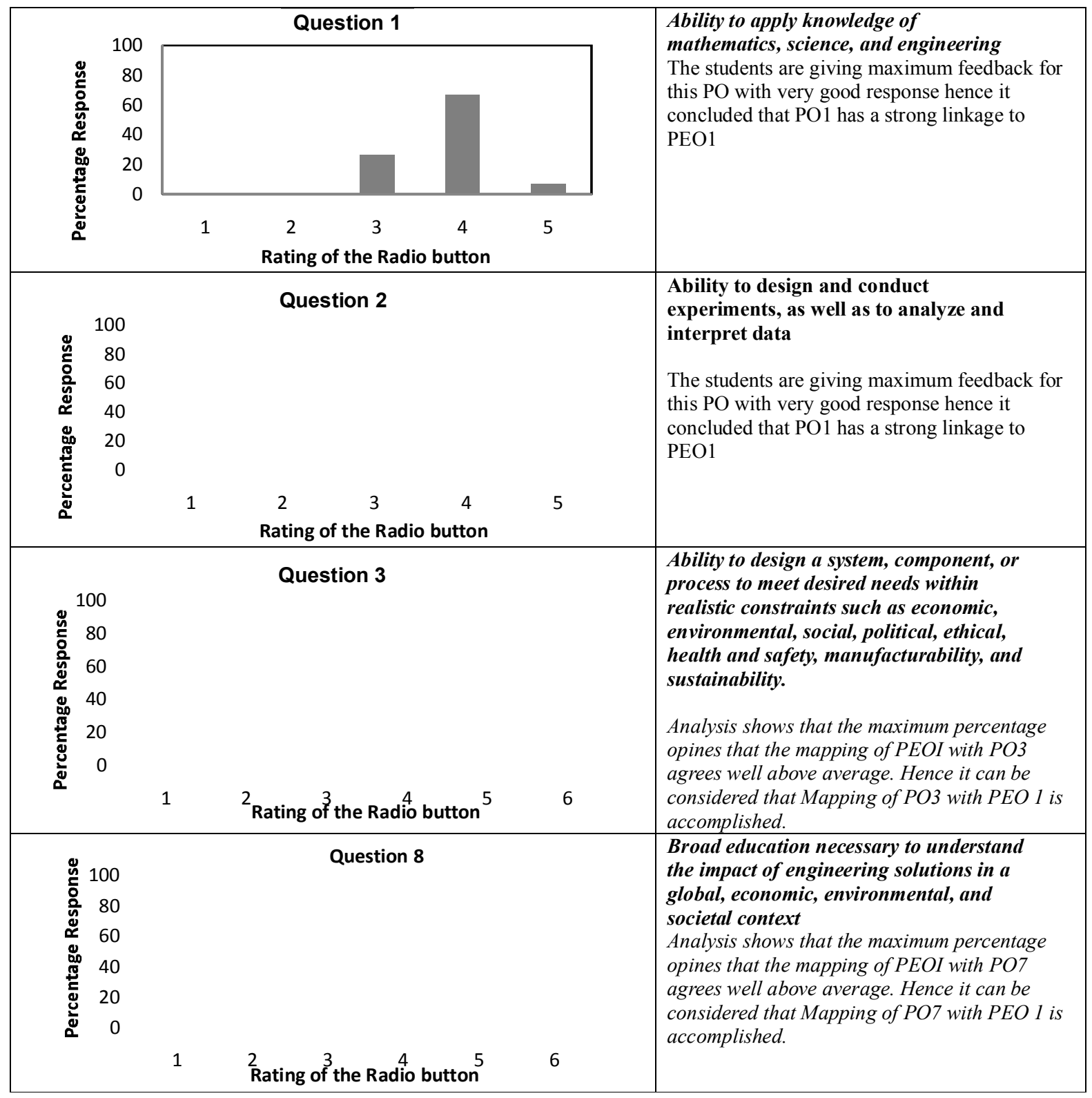

Figure 3: Articulation of survey question with PEO1( Question number are same as Table 2) 

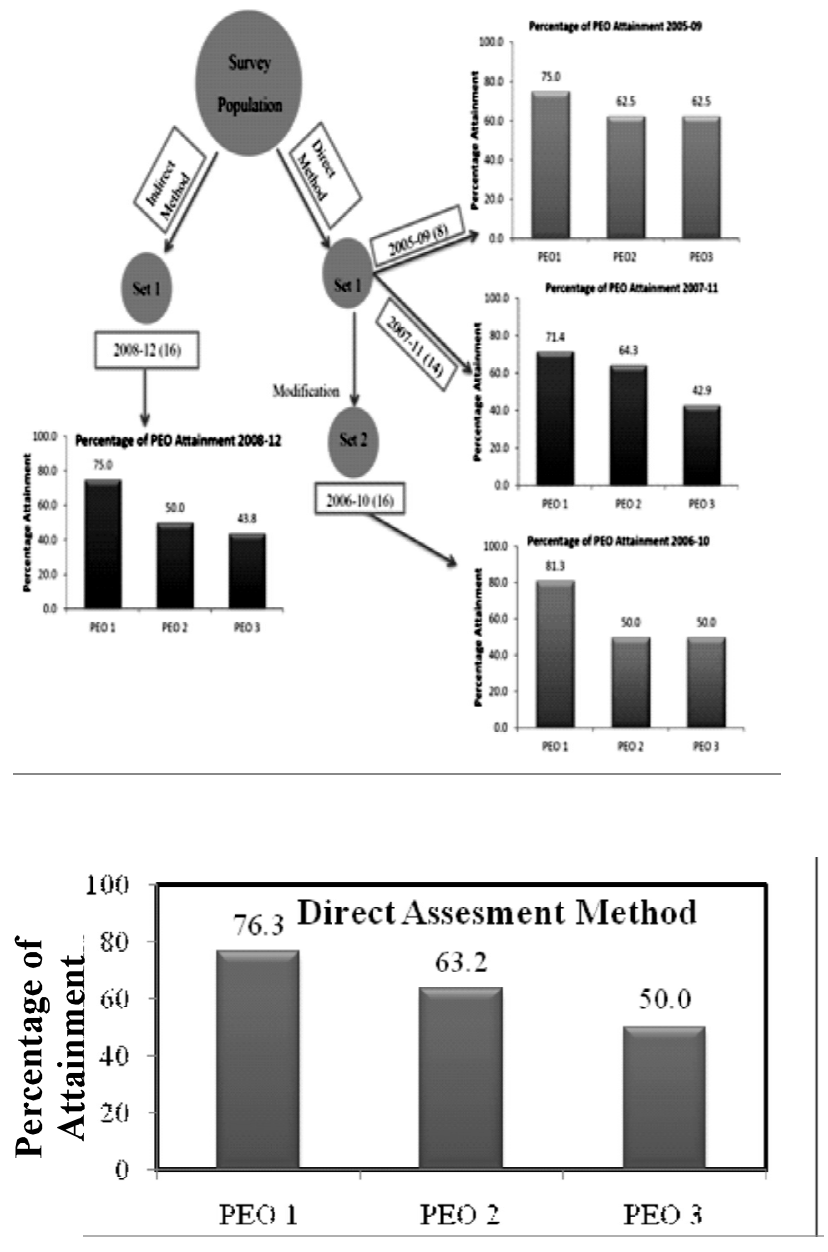

Figure 4: Overall Attainment of PEOs

\section{Conclusions}

The present paper mainly address with the design of the curriculum with main focus on the graduate attributes, vision \& mission of the Department and Program Education Objective of the Department with emphasis on institute vision and mission. The attainment of the PEOs is assessed from the alumni surveys this a direct assessment method and attainment of POs and mapping of these POs to PEOs are indirect assessment of PEOs. This process of defining the PEOs based on the assessed results is a continuous process as the syllabus changes based on the change in technology worldwide.

\section{References}

[1] www.nbaind.org

[2]zhamZainalAbidinet. Al, "Assessing the attainment of course outocmes for an engineering course",.Preceedings of the 2nd International Conference of Teaching and Learning (ICTL 2009), Malaysia.

[3] Nikos J. Mourtos, "A Systematic Approach For Defining And Assessing Program Educational Objectives And Outcomes"., Professor, Mechanical \& Aerospace Engineering, San Jose State University, California.

[4] A. Chuchalin, "Engineering Curriculum Design Based on Program Accreditation Criteria", Tomsk Polytechnic University, Tomsk, Russia. 